\title{
Assessment of Students' Science Knowledge Levels and Their Involvement with Argumentation
}

\author{
Hanife Hakyolu, Feral Ogan-Bekiroglu \\ Dogus University ${ }^{1}$, Marmara University ${ }^{2}$
}

\begin{abstract}
Research on argumentation in science education has expanded noticeably over the past two decades. Whereas there are some studies presenting the effects of argumentation on science knowledge development, there are only a few studies discovering the interrelationship between knowledge and argumentation. Therefore, the purpose of this study was to investigate a possible relationship between students' science knowledge levels and their involvement with argumentation. Case study design was guided to the research. The participants of the study were pre-service physics teachers. Argumentations were embedded in the method class. The participants' knowledge levels were assessed with open-ended questions. Although there are a few connections, the findings demonstrate no relationship between the students' knowledge levels and their involvement with argumentation.
\end{abstract}

\section{Introduction}

"It is an argument that we are likely to find the most significant way in which higher order thinking and reasoning figure in the lives of most people" [1]. Argumentation promotes critical thinking as well as an essential quality of the discourse to be acquired in academic education [2].

The practice of argumentation means the sociocultural activity of constructing, presenting, interpreting, criticizing, and revising arguments [3] [4] [5] [6]. An argument is a product of that practice meaning that typically it is the outcome of a process of arguing that involves both the arguer and the other [3] [4] [5] [6].

Although argumentation research in science education has increased for two decades, there is still a need to analyze the discourse of argumentation in the classroom and to find ways of explaining it that make the process clear and enable others to emulate it [7]. Therefore, students' engagement in scientific argumentations and their understanding of science was investigated in this current study.

\section{Argumentation and Science Learning}

Mason [8] pointed out that sharing cognition through collective reasoning and arguing could be an important pedagogical strategy to be promoted for knowledge construction and reconstruction in the classroom. She added that by explicating, comparing, and challenging ideas and explanations, students could recognize limitations, anomalies, and fallacies as well as values in their representations of the world.

Whereas there are some studies presenting the effects of argumentation on science knowledge development, there are only a few studies discovering the interrelationship between knowledge and argumentation. Crossa, Taasoobshirazib, Hendricksc and Hickeya [9], for example, reported that students tended to feel more comfortable and be more competent in arguing about concepts when they were sufficiently knowledgeable about that subject. Sadler and [10] suggested that science content knowledge could affect the manner in which individuals defended and justified their positions. Additionally, the results stated by von Aufschnaiter, Erduran, Osborne and Simon [11] proposed that students could acquire a higher quality of argumentation that consisted of well-grounded knowledge with a relatively low level of abstraction. This current study would contribute to the literature toward a better understanding of how argumentation is associated with knowledge levels in science.

\section{Purpose of the Study}

Students' willingness to acknowledge and deal with situations that may involve argument depends on their perceptions and interpretations of the purpose and the context of the task, and the learning situation [12]. However, within both Vygotskian and Piagetian traditions, the focus has been on the interaction process itself so that cognitive capacities of the individuals have not been examined [13]. Therefore, the purpose of this study was to investigate a possible relationship between students' 
science knowledge levels and their involvement with argumentation.

\section{Methodology}

Case study design [14] was guided to the research to examine the relationship between students' quantity and quality of arguments and their science content knowledge.

\subsection{Participants and Settings}

The participants of the study were 13 senior preservice physics teachers studying in the methods course. Their average age was 21 . Four of the participants were female. They had already completed all the necessary physics courses. It was the first time that the participants were being a part of argumentation context in the class

\subsection{Argumentation Sequences}

If both the number of argumentation and intervention time are raised, the quality of participants' argumentation increases [13]. Moreover, the context and content of argumentation affect participants' argumentation quality as well [3] [15]. For these reasons, three argumentations implemented in the methods course were promoted in the different contents and various contexts. The argumentations were related to the subjects of dynamics. The duration of each argumentation was approximately 50 minutes. The instructor of the class was one of the authors of this paper.

The participants had been taught in traditional environments in their courses until the methods course and not had any experience with argumentation as a teaching strategy. Since the preservice teachers had completed all of their physics courses and had previous knowledge of the physics subjects, the aim of the instruction was to provide opportunities for them to engage in argumentation process and to argue about scientific concepts instead of teaching physics. Table 1 presents content, related physics concepts and context for each argumentation.

Table 1. Content, concepts and context of argumentations

\begin{tabular}{|l|l|l|l|}
\hline & \multicolumn{3}{|l|}{ Argumentations } \\
\hline & First & Second & Second \\
\hline Content & $\begin{array}{l}\text { Motion of a } \\
\text { car }\end{array}$ & $\begin{array}{l}\text { Children } \\
\text { throwing } \\
\text { stones in a } \\
\text { pole }\end{array}$ & $\begin{array}{l}\text { Flying } \\
\text { sportsmen } \\
\text { wearing } \\
\text { wingsuits }\end{array}$ \\
\hline Concepts & $\begin{array}{l}\text { Velocity, } \\
\text { speed }\end{array}$ & $\begin{array}{l}\text { Projectile } \\
\text { motion }\end{array}$ & $\begin{array}{l}\text { Free fall, air } \\
\text { friction }\end{array}$ \\
\hline Context & $\begin{array}{l}\text { Explanation } \\
\text { for a } \\
\text { phenomenon }\end{array}$ & $\begin{array}{l}\text { Selection of } \\
\text { a scientific } \\
\text { claim }\end{array}$ & $\begin{array}{l}\text { Prediction, } \\
\text { observation, } \\
\text { explanation }\end{array}$ \\
\hline
\end{tabular}

Activities that encourage dialogic argumentation can provide a context whereby individuals are able to use each others' ideas to construct and negotiate a shared understanding of a particular phenomenon in the light of past experiences and new information [16]. Thus, all of the argumentations were dialogical where different perspectives were being examined and the purpose was to reach agreement on acceptable claims or courses of action [17].

The students worked as groups in the beginning of the argumentations and then, each group expressed their ideas in a whole-class discussion. Argumentation worksheets were distributed to the students at the beginning of each argumentation sequence. They wrote their final words or ideas in the worksheets before participating in the whole class discussion.

\subsection{Data Collection Methods}

A questionnaire including open-ended questions was administered to the participants before promoting three argumentation sequences in the class.

The questionnaire was composed of 13 factual, explanation and generation questions and designed to examine students' understanding of dynamics. This questionnaire measured the following seven fundamental concepts and their applications in general: velocity, acceleration, force, friction, gravitation, free fall, air friction, range, and flight time. Some of the questions measured more than one concept. The questionnaire was developed by the authors, who are physics educators. The content validity of the questionnaire was ensured with two more experts.

The participants and the instructor were videotaped during the instruction. In addition, the participants' voice records while they were arguing and their written arguments were collected as data sources.

\subsection{Data Analysis}

The model developed by Chi and Roscoe [18] in order to represent the knowledge was used to analyze the participants' science understanding. Based on this categorization, participants' answers to the questionnaire were coded. If the whole response was consistent with the scientifically accepted perspective and had a majority of the key propositions, it was coded as 'complete correct'. Although it had sufficient explanation and a majority of the key propositions, if the whole response was not consistent with the scientifically accepted perspective, it was coded as 'complete flawed'. If the response included some correct scientific terminology but the explanation was not sufficient and had many missing pieces, it was coded as 
'incomplete correct'. If the response was not consistent with the scientifically accepted perspective and there was not enough explanation, it was coded as 'incomplete flawed'. If the response had inconsistent explanation from the beginning to the end and propositions were not interconnected in some systematic way, it was coded as 'incoherent (fragmented)'. If the respondent stated that she/he did not know the answer or if the responded left the answer blank, the response was coded as 'none'. The data was re-examined a few times to detect any response that did not fit into one of the knowledge categories.

The participants' argumentations were coded based on the scale developed by Clark and Sampson [16] with some additions to analyze their quality and quantity of arguments in detail. There are a few models in the literature to use in analysis of argumentation, such as Toulmin Analysis Pattern. Clark and Sampson's scale was chosen among the models because it is comprehensive to analyze most of the argumentation components. Clark and Sampson determined components of an argumentation for the quantitative analysis. According to their scale, 'claim' is the seedcomment principle or an assertion made by a pair of students. 'Counterclaim' is an assertion made by a pair of students that is different from (and does not attack) the seed claim or parent comment made by another pair of students. 'Change of Claim' is a comment made by a pair of students indicating that: (1) they have changed their original claim; or (2) changed their viewpoint; or (3) have made a concession in response to comments (claims or rebuttals) made by another pair of students. 'Rebuttal Against Grounds' is an attack on, or disagreement with, the grounds (evidence, explanations, qualifiers, or backing) used by another pair of students to support or justify their comment. 'Rebuttal Against Thesis' is an attack on or disagreement with the thesis of another pair of students' comment that does not attack the grounds. 'Clarification in response to a Rebuttal' is assigned to comments that are used to strengthen a position (in terms of accuracy or validity) in response to a rebuttal without attacking the rebuttal or grounds made by another pair of students. 'Support of a Comment' is a statement used to support the truth or accuracy of the previous claim or rebuttal. This category includes statements that: (1) voice agreement with a comment; (2) rewords the previous comment; (3) adds additional grounds in support; or (4) expands on the comment. 'Query about Meaning' is a comment that asks for clarification of an earlier comment. These comments question the meaning of a statement rather than the accuracy of the statement. 'Clarification of Meaning' is a comment made by a pair of students to clarify (restate in a new way) previous comment. The purpose of these comments is to clarify the meaning of a statement in response to a query (about meaning) rather than supporting the accuracy of a statement. 'Off-task' is the comment that is not about the topic.

However, 'support of a comment' was not used in the data analysis of this research in order to make separation between supporting of a claim with evidence and rewording or repeating of a claim. In addition to Clark and Sampson (2008)'s components, the following elements were emerged from our argumentation data: support of a claim with evidence (data), warrant (support of data), repeat of a support, repeat of a rebuttal, repeat of a claim, thinking, answer to a question (yes/no answers or one-word answers), question form, not completely convinced agreement, not convinced, unsure claim, no answer, not related to physics, and agreement.

Quality level of argumentation was determined in terms of the number and quality of rebuttals in the argumentation. Consequently, Level 5 means that argumentation involves multiple rebuttals and at least one rebuttal that challenges the grounds used to support a claim. Level 4 means that argumentation involves multiple rebuttals that challenge the thesis of a claim but does not include a rebuttal that challenges the grounds used to support a claim. Level 3 means that argumentation involves claims or counterclaims with grounds but only a single rebuttal that challenges the thesis of a claim. Level 2 means that argumentation involves claims or counterclaims with grounds but no rebuttals. Level 1 means that argumentation involves a simple claim versus counterclaim with no grounds or rebuttals. Level 0 means non-oppositional [16].

In order to do data reduction, the students' answers to the questions related to seven concepts were grouped under the following three main concepts: uniform motion, projectile motion, and force-friction. The codes of the students' knowledge levels based on the main concepts are presented in the second column of Table 2. The average knowledge levels (AKL) of the students were determined according to the main concepts and assigned from 1 to 5 , where 5 represents the highest average knowledge level (see the third column). If the student had two or three complete-correct codes, his/her AKL was assigned to 5. If the student had one complete correct code and at least one incomplete correct code, his/her AKL was assigned to 4. If the student had at least two incomplete correct codes and did not have any complete correct code, his/her AKL was assigned to 3 . If the student had only one incomplete correct code and did not have any complete correct code, his/her AKL was assigned to 2. Finally, if the student neither had complete correct code nor incomplete correct code, his/her AKL was assigned to 1.

The students' quantity of argumentation is based on the number of argumentation components (see the 
Table 2. The students' learning levels and their involvement with argumentation

\begin{tabular}{|c|c|c|c|c|c|c|c|c|c|c|c|}
\hline \multirow[t]{2}{*}{ Student } & \multirow{2}{*}{$\begin{array}{l}\text { Knowledge } \\
\text { Levels }\end{array}$} & \multirow[t]{2}{*}{ AKL } & \multicolumn{3}{|c|}{ First Argumentation } & \multicolumn{3}{|c|}{ Second Argumentation } & \multicolumn{3}{|c|}{ Third Argumentation } \\
\hline & & & QNA & AQNA & QLA & QNA & AQNA & QLA & QNA & AQNA & QLA \\
\hline $\mathbf{A}$ & $\begin{array}{l}\mathrm{CC}, \quad \mathrm{CC}, \\
\mathrm{CC}\end{array}$ & 5 & $\begin{array}{l}\mathrm{C}(25), \mathrm{C}-\mathrm{C}(5), \\
\mathrm{SC}(17), \\
\mathrm{RS}(1), \operatorname{RC}(6), \\
\operatorname{RAT}(6), \\
\operatorname{RAG}(2), \\
\mathrm{CM}(6), \operatorname{RR}(1)\end{array}$ & 5 & 4 & - & - & - & $\begin{array}{l}\mathrm{C}(14), \mathrm{SC}(11), \\
\mathrm{A}(3), \mathrm{RS}(2), \\
\mathrm{RC}(3), \mathrm{W}(1), \\
\mathrm{CM}(1)\end{array}$ & 3 & 1 \\
\hline $\mathbf{B}$ & $\begin{array}{l}\mathrm{IC}, \mathrm{CFL}, \\
\mathrm{CC}\end{array}$ & 4 & $\mathrm{C}(1), \mathrm{SC}(1)$ & 1 & 1 & $\mathrm{C}(1), \mathrm{SC}(1)$ & 1 & 1 & $\begin{array}{l}\mathrm{C}(5), \mathrm{SC}(8), \\
\mathrm{W}(1), \mathrm{ChC}(1), \\
\mathrm{A}(3)\end{array}$ & 2 & 1 \\
\hline $\mathbf{C}$ & $\begin{array}{l}\text { IC, IFL, } \\
\text { IFR }\end{array}$ & 2 & $\begin{array}{l}\mathrm{C}(7), \operatorname{RAG}(2), \\
\mathrm{SC}(5), \\
\operatorname{RAT}(1), \\
\text { QF(1), CM(1) }\end{array}$ & 2 & 4 & - & - & - & - & - & - \\
\hline $\mathbf{D}$ & $\begin{array}{l}\text { IFL, } \\
\text { IC }\end{array}$ & 4 & $\begin{array}{l}\text { QAM(2), } \\
\text { C(10), SC(1), } \\
\text { RAG(1), } \\
\text { CM(1), } \\
\text { ChC(1), A(1) }\end{array}$ & 2 & 3 & $\begin{array}{l}\mathrm{C}(19), \mathrm{C}-\mathrm{C}(2), \mathrm{SC}(4), \mathrm{AQ}(1), \\
\mathrm{CM}(4), \quad \mathrm{ChC}(2), \\
\mathrm{QF}(1), \operatorname{RAG}(1)\end{array}$ & 3 & 2 & $\begin{array}{l}\mathrm{C}(13), \mathrm{SC}(10), \\
\mathrm{W}(5), \mathrm{RC}(2)\end{array}$ & 3 & 1 \\
\hline $\mathbf{E}$ & $\begin{array}{l}\text { IC, } \quad \text { CC, } \\
\text { IFR }\end{array}$ & 4 & $\begin{array}{l}\mathrm{C}(3), \mathrm{SC}(2), \\
\mathrm{CM}(2)\end{array}$ & 1 & 2 & $\begin{array}{l}\mathrm{C}(13), \mathrm{C}-\mathrm{C}(2), \mathrm{SC}(6), \mathrm{W}(1), \\
\mathrm{RC}(2), \mathrm{RAT}(1), \mathrm{T}(2), \mathrm{AQ}(1), \\
\mathrm{CM}(7), \quad \mathrm{ChC}(1), \\
\mathrm{NA}(1), \\
\operatorname{RS}(1)\end{array}$ & 3 & 2 & $\begin{array}{l}\mathrm{C}(7), \mathrm{SC}(6), \\
\mathrm{NCCA}(1), \\
\mathrm{W}(1)\end{array}$ & 2 & 1 \\
\hline $\mathbf{F}$ & $\begin{array}{l}\text { IFR, IFR, } \\
\text { IFR }\end{array}$ & 1 & $\begin{array}{l}\mathrm{C}(2), \mathrm{SC}(1), \\
\mathrm{QF}(2), \mathrm{CM}(1), \\
\mathrm{NC}(2), \mathrm{NA}(1)\end{array}$ & 1 & 1 & $\begin{array}{l}\mathrm{C}(12), \mathrm{SC}(2), \mathrm{RC}(3), \mathrm{ChC}(1), \\
\mathrm{CM}(1), \operatorname{RAT}(2)\end{array}$ & 2 & 3 & - & - & - \\
\hline G & IC, IFR, IC & 3 & $\begin{array}{l}\mathrm{C}(6), \mathrm{SC}(5), \\
\operatorname{RAT}(2), \\
\operatorname{RAG}(1), \\
\mathrm{CM}(2), \mathrm{A}(2), \\
\mathrm{NC}(1)\end{array}$ & 2 & 5 & $\begin{array}{l}\mathrm{C}(15), \mathrm{SC}(2), \mathrm{C}-\mathrm{C}(2), \mathrm{RC}(6), \\
\mathrm{AQ}(1), \quad \mathrm{QAM}(2), \\
\mathrm{A}(1), \operatorname{RAT}(1)\end{array}$ & 2 & 1 & $\begin{array}{l}\mathrm{C}(4), \mathrm{SC}(1), \\
\mathrm{A}(1)\end{array}$ & 1 & 1 \\
\hline $\mathbf{H}$ & $\begin{array}{l}\text { IFR, IC, } \\
\text { IFR }\end{array}$ & 2 & $\begin{array}{l}\text { C(4), C-C(1), } \\
\text { SC(3), RS(1), } \\
\text { ChC(1) }\end{array}$ & 1 & 2 & - & - & - & $\begin{array}{l}\text { C(15), SC(12), } \\
\text { W(2), RC(4), } \\
\text { ChC(1), } \\
\text { AQ(1), } \\
\text { QAM(1) }\end{array}$ & 3 & 1 \\
\hline
\end{tabular}




\begin{tabular}{|c|c|c|c|c|c|c|c|c|c|c|c|}
\hline $\mathbf{I}$ & $\begin{array}{l}\text { IFR, IC, } \\
\text { IFR }\end{array}$ & 2 & $\begin{array}{l}\mathrm{C}(10), \mathrm{SC}(1), \\
\mathrm{A}(2), \mathrm{RC}(3), \\
\mathrm{CM}(1), \\
\mathrm{RAG}(1), \\
\mathrm{ChC}(2)\end{array}$ & 2 & 2 & $\begin{array}{l}\mathrm{C}(9), \mathrm{C}-\mathrm{C}(3), \mathrm{SC}(6), \mathrm{RS}(1), \\
\mathrm{CM}(2), \mathrm{RAG}(1)\end{array}$ & 2 & 2 & $\begin{array}{l}\mathrm{C}(3), \mathrm{SC}(5), \\
\mathrm{RC}(2), \mathrm{A}(1)\end{array}$ & 1 & 1 \\
\hline $\mathbf{J}$ & $\begin{array}{ll}\text { IFR, IFR, } \\
\text { none }\end{array}$ & 1 & $\begin{array}{l}\mathrm{C}(15), \mathrm{SC}(9), \\
\mathrm{RAG}(1), \\
\mathrm{CM}(4), \\
\operatorname{RAT}(1), \\
\mathrm{ChC}(1), \mathrm{A}(1)\end{array}$ & 3 & 2 & $\begin{array}{l}\mathrm{C}(10), \mathrm{SC}(4), \mathrm{RAG}(2), \mathrm{W}(1), \\
\mathrm{RC}(2), \operatorname{RAT}(1), \mathrm{A}(1)\end{array}$ & 2 & 3 & $\begin{array}{l}\mathrm{SC}(5), \mathrm{RS}(2), \\
\mathrm{T}(1), \mathrm{CM}(1), \\
\mathrm{ChC}(1), \mathrm{A}(2)\end{array}$ & 1 & 1 \\
\hline $\mathbf{K}$ & $\begin{array}{ll}\text { IFL, } & \text { IFL, } \\
\text { IFR } & \end{array}$ & 1 & $\begin{array}{l}\mathrm{C}(6), \mathrm{C}-\mathrm{C}(1), \\
\mathrm{CM}(2), \mathrm{A}(1), \\
\mathrm{RR}(1), \mathrm{QF}(1), \\
\mathrm{ChC}(1), \\
\mathrm{NCCA}(1), \\
\mathrm{NC}(1), \mathrm{SC}(1), \\
\operatorname{RAG}(1), \\
\operatorname{RAT}(1), \mathrm{T}(1)\end{array}$ & 1 & 1 & $\begin{array}{l}\mathrm{C}(22), \mathrm{C}-\mathrm{C}(2), \mathrm{SC}(9), \mathrm{RC}(1), \\
\mathrm{RAG}(2), \mathrm{QF}(2), \mathrm{ChC}(1), \mathrm{T}(1), \\
\mathrm{CM}(1), \mathrm{A}(1), \operatorname{RAT}(3)\end{array}$ & 4 & 3 & - & - & - \\
\hline $\mathbf{L}$ & $\begin{array}{ll}\text { IFR, } & \text { IC, } \\
\text { IFR } & \end{array}$ & 2 & - & - & - & $\mathrm{SC}(1), \mathrm{C}(1)$ & 1 & 1 & - & - & - \\
\hline $\mathbf{M}$ & $\begin{array}{l}\text { none, none, } \\
\text { IFR }\end{array}$ & 1 & - & - & - & $\begin{array}{l}\mathrm{C}(6), \mathrm{C}-\mathrm{C}(1), \mathrm{SC}(3), \mathrm{QAM}(1), \\
\mathrm{CM}(2), \mathrm{ChC}(1)\end{array}$ & 1 & 1 & $\begin{array}{l}\mathrm{C}(2), \mathrm{SC}(2), \\
\mathrm{AQ}(1)\end{array}$ & 1 & 1 \\
\hline
\end{tabular}

AKL: Average Knowledge Level, QNA: Quantitative of Argumentation, AQNA: Average QNA, QLA: Qualitative of Argumentation,

CC: Complete-Correct, IC: Incomplete-Correct, IFR: Incomplete-Fragmented, IFL: Incomplete-Flawed, CFL: Complete-Flawed, CFR: Complete-Fragmented.

C: Claim, C-C: Countel SC: Support of a Claim, W: Warrant, RS: Repeat of a Support, RR: Repet of a

grounds, T: Thinking, AQ: Answer to question, QAM: Query about meaning, CM: Clarification of meaning, QF: Question form, ChC: Che

NC: Not convinced, UC: Unsure claim, NA: No answer, OT: Off-task, NRP: Not related to physics, A: Agreement, -: the student was not in the class 
fourth, seventh, and tenth columns of Table 2). Average quantity of argumentation (AQNA) was determined according to the number of components (see the fifth, eighth, and eleventh columns of the table). In this determination, repeated components, thinking, answering, agreement, persuasion, and irrelevancy was not counted. If the number of components in each argumentation was between 49 and 60, AQNA was coded as 5. If the number of components was between 37 and 48, AQNA was coded as 4 . If the number of components was between 25 and 36, AQNA was coded as 3 . If the number of components was between 13 and 24, AQNA was coded as 2. Finally, if the number of components was between 1 and 12, AQNA was coded as 1 .

The coding scheme of 1 through 5 was used both in the knowledge levels and in the quantity of argumentation to be able to look for a relationship between two phenomena. The students' quality of argumentations (QLA) was already based on fivelevel scale (see the sixth, ninth, and twelfth columns of Table 2).

\section{Results and Discussion}

The students' knowledge levels, their quantitative involvement with three argumentations and their qualitative involvement with three argumentations are shown in Table 2.

According to Table 2, there are only a few connections between the students' learning levels and their quantitative and qualitative engagement in argumentations. These connections are illustrated as bold numbers in the table. For example, Student A had the highest average knowledge level (5) and his average quantitative contribution to the first argumentation was also highest (5). That is, he produced many claims and supported most of his claims. His qualitative contribution to the first argumentation was high (4), too and he created multiple rebuttals. However, he did not continue his high performance and both AQNA and QLA values decreased at the third argumentation. Another example for the connection can be given for Student M. He had the lowest knowledge level (1). In other words, his propositions were incoherent with scientific claims. Similarly, he produced little number of claims and did not create any rebuttals during the second and third argumentations. Therefore, his average quantitative contributions and average qualitative contributions to the second and third argumentations were assigned to 1. Apart from $\mathrm{A}$ and $\mathrm{M}$, the connection between knowledge level and involvement with argumentation (both qualitatively and quantitatively) was observed in Student F's performance for the first argumentation, in Student I's performance for the first and second argumentations, in Student J's performance for the third argumentation and in Student K's performance for the first argumentation. However, there was no continuous and consistent connection between the participants' AKL values and their AQNA and QLA values. Therefore, the findings presented no relationship between the students' science knowledge levels and their involvement with argumentation. In other words, students who have scientifically correct knowledge do not always produce large number of argumentation components and quality rebuttals.

The result of this study is in line with the results of other research [19] [20]. For instance, Kuhn [19] came across that experts in a domain did not show better forms of argumentative thinking in the domain of their expertise than they did about other topics. Nevertheless, the current result seems to be in contradiction with the results of Means and Voss [21], who found that prior knowledge was related to some aspects of argumentative thinking, such as generating more reasons or stating more qualifiers.

\section{Suggestion and Implication of the Study}

It is suggested that students' knowledge levels cannot be used as a predictor for their contribution to an argumentation. This study adds to the literature by investigating the relationship between argumentation and knowledge level.

\section{References}

[1] D. Kuhn, "Thinking as argument", Harvard Educational Review, 1992, 62(2), pp. 155-178

[2] A. Veerman, J. Andriessen, and G. Kanselaar, "Collaborative argumentation in academic education", Instructional Science, 2002, 30, pp. 155-186.

[3] A. Duschl, and J. Osborne, "Supporting and promoting argumentation discourse in science education", Studies in Science Education, 2002, 38, pp. 39-72.

[4] Johnson, R. H., Manifest rationality: A pragmatic theory of argument, New Jersey, Lawrence Erlbaum, 2000.

[5] S. Leita o, "The potential of argument in knowledge building”, Human Development, 2000, 43, pp. 332-360

[6] van Eemeren, F. H., Grootendorst, R., Henkemans, F. S., Blair, J. A., Johnson, R. H., Krabbe, E. C. W., Plantin, C., Walton, D. N., Willard, C. A., Woods, J., and Zarefsky, $\mathrm{D}$, Fundamentals of argumentation theory: A handbook of historical backgrounds and contemporary developments, Mahwah, NJ, Lawrence Erlbaum Associates, 1996.

[7] Boulter, C. J., and Gilbert, J. K., Argument and science education in P. J. M. Costello, and S. Mitchell (Eds.), Competing and consensual voices: The theory and practice 
of argumentation, Clevedon, Multilingual Matters, 1995, pp. $84-98$

[8] L. Mason, "Sharing cognition to construct scientific knowledge in school context: The role of oral and written discourse", Instructional Science, 1998, 26, pp. 359-389.

[9] D. Crossa, G. Taasoobshirazib, S. Hendricksc, and D. T. Hickeya, "Argumentation: A strategy for improving achievement and revealing scientific identities", International Journal of Science Education, 2008, 30(6), pp. 837-861.

[10] T. D. Sadler, and S. R. Fowler, "A threshold model of content knowledge transfer for socioscientific argumentation", Science Education, 2006, 90, pp. 9861004

[11] C. von Aufschnaiter, S. Erduran, J. Osborne, and S. Simon, "Arguing to learn and learning to argue: Case studies of how students' argumentation relates to their scientific knowledge", Journal of Research in Science Teaching, 2008, 45(1), pp. 101-131

[12] Perret-Clermont, A., Perret J. A., and Bell N., "The social construction of meaning and cognitive activity in elementary school children in L. B. Resnick, J. M. Levine, and S. D. Teasley (Eds.), Perspectives on socially-shared cognition, Washington, DC, American Psychological Association, 1991, pp. 41-62

[13] D. Kuhn, W. Shaw, and M. Felton, "Effects of dyadic interaction on argumentative reasoning", Cognition and Instruction, 1997, 15(3), pp. 287-315

[14] Stake, R., The art of case-study research, Thousand Oaks, CA, Sage, 1995

[15] G. J. Kelly, S. Druker, and C. Chen, "Students' reasoning about electricity: Combining performance assessments with argumentation analysis", International Journal of Science Education, 1995, 20(7), pp. 849-871.

[16] D. B. Clark, and V. Sampson, "Assessing dialogic argumentation in online environments to relate structure, grounds, and conceptual quality", Journal of Research in Science Teaching, 2008, 45 (3), pp. 293-321

[17] R. Driver, P. Newton, and J. Osborne, "Establishing the norms of scientific argumentation in classrooms", Science Education, 2000, 84, pp. 287-312.

[18] Chi, M. T. H., and Roscoe, R. D., The process and challenges of conceptual change in M. Limon, and L. Mason (Eds.), Reconsidering conceptual change: Issues in theory and practice, Dordrecht, The Netherlands, Kluwer Academic Publishers, 2002, pp. 3-27

[19] Kuhn, D., The skills of argument, Cambridge, England, Cambridge University Press, 1991

[20] Perkins, D.N., Farady, M., and Bushey, B., Everyday reasoning and the roots of intelligence in J. F. Voss, D.N. Perkins, and J. W. Segal (Eds.), Informal reasoning and education, Hillsdale, Erlbaum 1991, pp. 83-105
[21] L. M. Means, and J. F. Voss, "Who reasons well? Two studies of informal reasoning among children of different grade, ability, and knowledge levels", Cognition and Instruction, 1996, 14(2), pp. 139-178 